Mansirova S.A.

DOI: $10.25045 /$ jpis.v10.i2.03

National Aviation Academy, Baku, Azerbaijan

avia-mexanik@mail.ru

\title{
PRACTICAL DESCRIPTION FOR THE MAJOR COMPONENTS OF VIRTUAL FLIGHT SIMULATORS
}

\author{
Received: 23.12.2018 Revised: 06.05.2019 Accepted: 27.05.2019
}

This article describes the main components of virtual flight simulators, and how a fully functioning simulator is built from them. The main goal of the virtual simulator is to help the pilot to achieve, test and maintain aircraft control skills without any risk to property or life and at much lower cost than airborne training.

Keywords: Virtual flight simulator, 3D glasses, virtual cockpit, set of programs, virtual reality (VR), Flight dynamics, pilot training.

\section{Introduction}

Modern three-dimensional virtual reality development is progressing in several key areas of computing technology. High-quality 3D glasses for the visualization of three-dimensional scenes are bought affordably. High-performance graphics processors were developed especially for personal computers, which allow real-time creation of dynamic 3D scenes. Finally, electronic systems for tracking the position the operator's hands and head were created to manipulate the objects in virtual reality. It became obvious that the traditional full-size and very expensive airplane simulators can be supplemented by a thousand times cheaper "virtual simulators". Of course, virtual simulators cannot fully immerse a person in virtual reality for the sole reason that the pilots in full-size simulators are holding (that is, "feeling") the instruments in the cockpit. Nevertheless, as practice shows, if one amends a real steering wheel, gas stick and pedals to the virtual reality in 3D glasses, the virtual control of airplanes becomes close to the real one. A further approach to reality is achieved by placing the pilot's seat on a compact dynamic platform (hexapod or tripod), which simulates such effects as acceleration, turbulence, hard landing, etc.

The main goal of the virtual simulator is to help the pilot to achieve, test and maintain aircraft control skills without any risk to property or life and at a much lower cost than airborne training. On virtual simulators, experienced pilots can regularly and independently create and work out all sorts of abnormal situations, as well as learn how to manage additional aircraft models. Following the latest modifications to the aircraft thanks to the flexibility of the mathematical software of virtual simulators, any change can be promptly made to the virtual cockpit model to reflect the latest aircraft modifications, compared to the high expense of similar modifications to a full-size simulator. For the development teams, as well as for individuals, who want to interested in starting to use virtual simulators, it is initially very difficult to understand the puzzle of the components of virtual simulators to ensure an informed choice among the available virtual simulators. Therefore, in this article, we describe the main virtual simulator software components, and report the available development firms for each such component. In addition, we describe the most popular virtual flight simulators, their component composition and the degree of user accessibility.

\section{Flight simulators}

A flight simulator is a device that artificially re-creates aircraft flight and the environment in which it flies, for pilot training, design, or other purposes. It includes replicating the physics that govern how aircraft fly, how they react to the applications of flight controls, the effects of other aircraft systems, and how the aircraft reacts to external factors such as air density, turbulence, wind shear, cloud, precipitation, etc. Virtual simulators include a set of programs that are responsible for various aspects of flight simulation and flight control systems. It includes a highresolution 3D model of the aircraft (CESSNA, Boing707, ...), including geometry and textures. 
Separately, there is also a corresponding cockpit model containing all navigation and flight control tools.

The components of simulator software consist of the following components:

- Aircraft models

- Airport models

- View of the underlying surface (scene, terrestrial)

- Weather models

- Models of aircraft flight dynamics (including sound)

- Mission purpose (missions)

A simple flight simulator system consists of several displays that simulate the view from the cockpit window; control devices (steering wheel, throttle, pedals); audio systems to simulate the sound of engines and speech commands of the controller. Virtual simulators additionally contain optical means for immersing the pilot in a virtual three-dimensional reality, as well as computer programs that calculate it in real time.

\section{Existing popular flight simulators}

Currently, there are about a dozen popular flight simulators. The most developed of them we describe in detail:

- Microsoft Flight Simulator

- P3D - Lockheed Martin Prepar3D

- Microsoft Flight Simulator X (FSX)

- X-Plane

- Microsoft Flight Simulator 2004

- GeoFS

- FlyInside

The most famous of the early virtual simulators is Microsoft Flight Simulator (MSFS), which was created in 1982. In 1998, the representatives of the Boeing Corporation began to participate in the further development of MSFS. MSFS's library of models of many large airports in the world, with realistic images of buildings and runways, a reliable landscape of the Earth, the ability to create naturalistic weather conditions, high quality of the instrument panel image, made it one of the best simulators in its class. Soon, the autopilot, the control room, and even the ability to download real-world weather conditions for the flight directly from the Internet were provided The traffic of airplanes scheduled and supervised by air traffic control services was also simulated. The most important feature of MSFS is that it is openness for users to create their own models of airliners and airports [3].

In 2009, Lockheed-Martin acquired the intellectual property (including source code) for Microsoft's Enterprise Simulation Platform (ESP). Microsoft ESP is the commercial version of Flight Simulator X SP2. In May 2010, Lockheed-Martin announced that thea new product called Prepar3D, based on the ESP source code, would be called Prepar3D. The product enables the use of hundreds of types of aircraft for the training purposes. In addition to the fact that the database includes the main airports of the world in 3D geometry, it also allows the user to make additions or corrections on their own, including adjusting the flight dynamics of a virtual aircraft. The company opened interface standards, hundreds of companies around the world began to offer additions to Prepar3D (the so-called "addons"), such as additional aircraft models, negotiations with flight dispatchers, monitoring of the training process with instructors in real time, cooperation between the first and co-pilot, etc. [2].

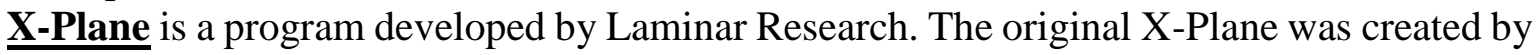
Austin Mayer to simulate the Piper Archer aircraft in a version for Mac OS X. Later versions for Windows and Linux were released. Users believe that X-Plane is inferior to MSFS in realism of aircraft control. Reproduction of aircraft models, weather and physics in X-Plane, with good 
technical characteristics of the processor and video card, are at a high enough level [1]. The XPlane user community is not as broad as MSFS, but continues to grow. This is facilitated by the presence of editors supplied with the simulator with convenient interfaces. In June 2018, the current version is X-Plane 11.11 was .released.

Microsoft Flight Simulator 2004 (known as FS2004) set the benchmark for PC flight simulators, and the environment engine. Many aspects of the simulator were changed; from weather settings and generation to the newly included auto-generation scenery features (computer generated trees and other objects) [5]. The world environment was a serious upgrade from FS2002 and FS2004 and shortly became the most popular flight simulator of all time. Even after the release of FSX, many avid flight simmers and users still think ofestimmate FS2004 as the "ultimate" simulator and prefer it over later versions, claiming that the package is more stable, more tried and tested [4].

GeoFS is a free, online flight simulator, with global scenery, that runs on the web browser. There are 20 available aircrafts (+ community contributed), ranging from para-glider to airliners. GeoFS is built on top of Cesium, a 3D globe technology (just like as Google Earth) that can provide global, highly detailed, and photo-realistic landscape. When flying GeoFS, the pilot is provided with global, 10 meters resolution, satellite images mapped over a high-resolution mesh (30 meter, down to 1 meter in some regions). To enhance realism, one can subscribe to GeoFS HD and fly over high resolution, photo-realistic aerial images. GeoFS HD is particularly suitable for visual flight rules practice [7].

FlyInside Flight Simulator, the crowdfunded VR plugin for Microsoft Flight Simulator X (2006), was built well before the first-party VR motion controllers existed, developed back in the DK2-era of 2015 as an ad hoc way of jumping into an already highly-detailed flight sim. Now, the creators of FlyInside FSX have released their own dedicated flight simulator in beta, dubbed FlyInside Flight Simulator, that's built from the ground-up for VR. FlyInside Flight Simulator is notn't hitting Steam or the Oculus Store yet though, as the company is launching beta access for both their free trial version and a paid 'pro version' first through their website to get the valuable feedback and start building a community around the fledgling flight sim [6].

\section{Aircraft models}

An aircraft is a machine that is able to fly by gaining support from the air. It counters the force of gravity by using either static lift or by using the dynamic lift of an airfoil, or in a few cases the downward thrust from jet engines. Common examples of aircraft include airplanes, helicopters, airships (including blimps), gliders, and hot air balloons. The human activity that surrounds aircraft is called aviation. The science of aviation, including designing and building aircraft, is called aeronautics. Aircraft may be classified by different criteria, such as lift type, aircraft propulsion, usage and others [10].

\section{Parts of a Plane}

The body of the plane is called the fuselage. It is generally a long tube shape. The wheels of a plane are called the landing gear. There are two main wheels on either side of the plane fuselage. Then there is one more wheel near the front of the plane. The brakes for the wheels are like the brakes for cars. They are operated by pedals, one for each wheel. Most landing gear can be folded into the fuselage during the flight and opened for landing [8]. All planes have wings. The wings are shaped with smooth surfaces. The smooth surfaces are slightly curved from the front or leading edge, to the back or trailing edge. Air moving around the wing produces the upward lift for the airplane. The shape of the wings determines how fast and high the plane can fly. A cut through the wing from front to back is called an airfoil. The hinged control surfaces are used to steer and control the airplane. The flaps and ailerons are connected to the backside of the wings. The flaps slide back and down to increase the surface of the wing area. They also tilt down to increase the curve of the wing. The slats move out from the front of the wings to make the wing 
space larger. This helps to increase the lifting force of the wing at slower speeds like takeoff and landing. The ailerons are hinged on the wings and move downward to push the air down and make the wing tilt up. This moves the plane to the side and helps it turn during flight. After landing, the spoilers are used like air brakes to reduce any remaining lift and slow down the airplane.

The tail at the rear of the plane provides stability. The fin is the vertical part of the tail. The rudder at the back of the plane moves left and right to control the left or right movement of the plane. The elevators at the rear of the plane can be raised or lowered to change the direction of the plane's nose. The plane will go up or down depending on the direction of that the elevators are moved.

Products for aircraft models include [11]:

- Flight1 Super King Air B200

- iFly Jets - The 747-400

- Pilatus PC-12, Flight1 Cessna Mustang

- Flight1 T182T, December 71941 Pearl Harbor

- Flight One 441 Conquest II, American Champion Aircraft - Scout / Citabria / Decathalon

- $\quad$ 421C Golden Eagle, Balsa Model

- VirtualPilot3D

- RealFlight

- Il-2 Sturmovik: 194

- Aerofly FS 2 Flight Simulator

\section{Flight dynamic}

Flight dynamics is the study of the performance, stability, and control of vehicles flying through the air or in outer space. It is concerned with how forces acting on the vehicle influence its speed and attitude with respect to time [13]. Aircraft share a critical interest in their orientation with respect to the earth horizon and heading, and this is represented by another set of angles, "yaw", "pitch", and "roll", which angles match their colloquial meaning, but also have formal definition as an Euler matrix of rotation. These angles are the product of the rotational equations of motion, where orientation responds to torque, just as the velocity of a vehicle responds to forces (Fig.1). Flight simulators allow custom-create from a scratch (or modify existing) aircraft's flight dynamic. As an example, let see how is done in Prepar3D [15].

The AIR files are used to provide flight dynamics data, in the form of coefficients and data tables, that determine the flying parameters. Considerable experience with flight dynamics is a requirement in order to understand the provided samples and make qualitative changes to them:

- Aerodynamics

- Ground effects

- Control input parameters

- Angle of Attack modifiers

- Mach tables

- Engine tuning parameters

- Propeller tuning parameters

- P.I.D controllers (used only by Artificial Intelligence controlled airplanes)

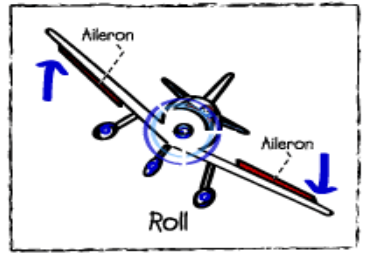

Picture of plane in roll

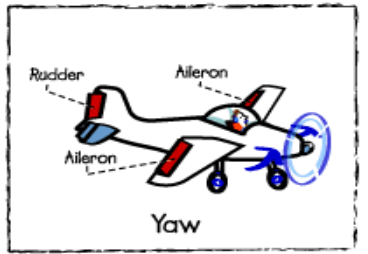

Picture of plane Yaw

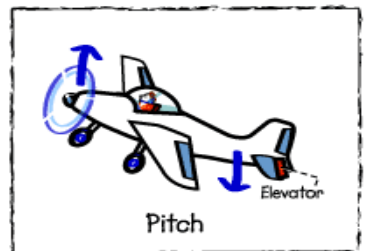

Picture of Plane Pitch 
Figure 1. Angles of rotation

To build an AIR file, one must navigate to the SimObject SDK\Flight Model SDK folder. This folder contains the Asm2Air tool and a Samples folder that contains the sample AIR files. The data in an ASM file is compiled into an AIR file using Asm2Air.exe. This will result in a file called PistonSample.air that must be placed in an aircraft configuration folder, and reference it from the aircraft configuration file (Go to to the Sim= entry of the Aircraft Configuration File [14]). Most of the base aerodynamic coefficients have a corresponding lookup table based on mach value. The output of each table enables the base constant coefficient to be offset (added to if the mach table entry is positive, subtracted from if the entry is negative) as a function of mach. Each table is fixed in size and resolution. The range is 0 to 3.2 mach with 17 entries. Linear interpolation is used to calculate the actual value used from any of the tables. In the case the aircraft is under AI control, the Proportional-Derivative-Integral controller (PID), takes an error for a controlled state and outputs a correction. For example, on an airspeed controller, the error would be the desired airspeed minus the current airspeed.

The output is then determined by the sum of three factors using the error and the P, I, and D constants. The "P" factor is simply a factor proportional to the error. The "I" factor is an accumulated factor scaled by the error. The "D" factor is a factor based on the rate of change of the error:

"P factor" $=\mathrm{P} *$ error

"Accumulated I factor" = "Accumulated I factor" + (I* error * deltaTime $)$, in Calculus terms, this is simply an integral. The error must reverse its sign to drive this accumulated factor to 0 . This is characterized as oscillations but drives the error to zero. "D factor" $=\mathrm{D} *$ error/deltaTime. As the error gets smaller, this drives the output to be asymptotic towards the desired value.

Among other tasks, the AI controls can be useful for an automated training of pilot on the flight simulator.

\section{Airports}

An airport is an aerodrome with extended facilities, mostly for commercial air transport. Airports often have facilities to store and maintain aircraft, and a control tower. An airport consists of a landing area, which comprises an aerially accessible open space including at least one operationally active surface such as a runway for a plane to take off or a helipad, and often includes adjacent utility buildings such as control towers, hangars and terminals. Larger airports may have airport aprons, taxiway bridges, air traffic control center, passenger facilities such as restaurants and lounges, and emergency services [17].

Creators of airport models include [11]:

- Drzewiecki Design

- FlexSim, SimAirport

- Airport Simulator 2019

- Talumis

Drzewiecki Design is a company specializing in software development for flight simulators. These products are designed for professional pilot training as well as for the use by flight simulation enthusiasts worldwide. Software is compatible with a wide range of flight simulation platforms. The company creates 3D visualizations of real-world areas - from airstrips to metropolitan areas with thousands of custom-made buildings and several international airports [16].

Products that work with Drzewiecki Design:

- Lockheed Martin Prepar3D

- Microsoft Flight Simulator X

- X-plane 
- Microsoft Flight Simulator 2004

Baku $\mathbf{X}$ is the first commercial scenery of Azerbaijan, featuring a highly detailed representation of UBBB Heydar Aliyev airport (Fig.2), as well as lite models of all other Azerbaijani airports, Baku city with hundreds of landmarks and the whole-country photoreal ground. This product is compatible with FSX and Prepar3D. Baku is the capital and largest city of Azerbaijan, as well as the largest city on the Caspian Sea and of the Caucasus region. Baku is located 28 meters ( $92 \mathrm{ft}$ ) below sea level, which makes it the lowest lying national capital in the world and also the largest city in the world located below sea level.

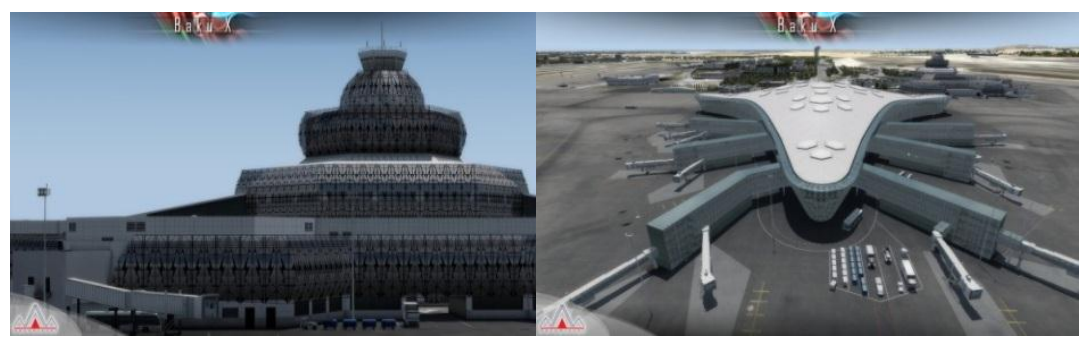

Figure2. Heydar Aliyev International Airport

Installation of Baku X: Simply execute the installer. Make sure that no duplicated AFCAD files are installed. The scenery will be automatically added to the Flight Simulator Scenery Library. The installer provides many configuration options.

\section{Scenery features:}

- Detailed model of UBBB Heydar Aliyev International Airport in Baku

- UBBB with 3D people, high quality static aircraft, custom animations, rain effects, VGDS

- SODE animated jetways and advanced interior modeling (Terminal 1, tower, Silkway hangar)

- Baku city with hundreds of custom-made landmarks, night textures, detailed autogen

- Lite models of Lenkoran, Ganja, Nakhchivan, Qabala, Zaqatala and Zabrat

- Enhanced AFDs with library objects for Dollyar AFB, Nasosnaya AFB, Stepanakert, Kyurdamir AFB, Balakari, Akstafa, Kala AFB, Yevlakh and Naftalan

- Custom-made UBBB airport charts included

\section{Scenery (terrain)}

A scenery refers to software used to create landscape images, 3D models, and animations. Basic elements of landscapes created by scenery generators include terrain, water, foliage, clouds, etc. Users typically use either custom or purchased engines that contain their own scenery generators. For some applications they use a procedurally generated terrain. Procedural texturing is a powerful technique. In the default rendering scheme, the terrain of a certain landclass is painted with a predefined texture, then the light is computed and this is what is shown on the screen. Procedural texturing does not use a pre-defined texture, but computes the texture as part of the rendering process. This technique allows textures to be sensitive to the environment and hence simulate wet or dusty terrain, to create the actual texture as a mixture of various overlay textures which change dependingent on how steep the terrain is or to add snow cover with any density on the fly [18].

Products for model scenery include [20]:

- Ultimate Terrain X Version 2

- Ground Environment X

- Orbx - Global Range

- Instant Mission Maker

- FS Water, December 71941 Pearl Harbor 
- XpressSim Scenery Products

- Ultimate Traffic 2 Schedule

- Golden Age Simulations: Golden Age Air Racing Package

- FlightGear

\section{Weather}

Weather is the state of the atmosphere along the aircraft trajectory, describing for example the degree to which it is hot or cold, wet or dry, calm or stormy, clear or cloudy. Most weather phenomena occur in the lowest level of the atmosphere, the troposphere, just below the stratosphere [19].

There are several products for the weather use in flight simulators:

- REX4 Simulation [24]

- FS Global Real Weather [23]

- OpusFSI [22]

- FS98 FSClouds and Textures Pro [26]

\section{REX4 Simulation}

Weather Architect is a custom weather generator and weather engine allowing creation of complete weather systems on a map with accuracy down to a single degree in the latitude and longitude. Weather Architect is a first-of-its-kind weather creation utility that gives the complete control in developing detailed weather systems anywhere in the world, including over oceans where no weather stations exist within the simulator [24].

\section{Conclusion}

In this article, we adopted the approach that can be used efficiency of training are the main reasons for using simulators as training devices. Novice pilots can experience flight conditions and learn from mistakes without any risks. This frees instructors from increased concerns to ensure the safety of a real flight with a student. Deep training on the virtual flight simulator saves crew time, fuel and maintenance of a real aircraft. When simulating a flight, you can select the required environmental conditions can be selected, and repeat the practice of a certain flight phase can be repeated until this element is fully developed. On virtual simulators, experienced pilots can regularly and independently create and work out all sorts of abnormal situations, as well as learn how to manage new aircraft models. Following the latest modifications of the aircraft, thanks to the flexibility of the mathematical software of the virtual simulators, any change (for example, in the cockpit) can be promptly made to the virtual cockpit model. A similar modification of a fullsize simulator can be very expensive. A typical virtual simulator contains several dozens of aircraft models of aircraft, the list of which is constantly updated.

\section{References}

1. https://en.wikipedia.org/wiki/X-Plane_(simulator)

2. https://en.wikipedia.org/wiki/Microsoft_Flight_Simulator\#P3D_Lockheed_Martin_Prepar3D

3. https://en.wikipedia.org/wiki/Microsoft_Flight_Simulator_X

4. https://www.aerosoft.com/en/flight-simulation/prepar3d/aircraft/

5. https://flyawaysimulation.com/downloads.html

6. https://www.roadtovr.com/flyinside-flight-simulator-preview-promising-start-vr-nativeflying/

7. https://www.geo-fs.com/

8. https://www.grc.nasa.gov/www/k-12/UEET/StudentSite/airplanes.html

9. https://en.wikipedia.org/wiki/Flight_dynamics

10. https://en.wikipedia.org/wiki/Aircraft 
11. http://www.flight1.com/products.asp?m=Flight-One-Software

12. https://www.grc.nasa.gov/www/k-12/UEET/StudentSite/dynamicsofflight. html

13. https://en.wikipedia.org/wiki/Flight_dynamics

14. http://www.prepar3d.com/SDKv4/LearningCenter.php

15. http://www.prepar3d.com/SDKv3/LearningCenter/LearningCenter.php

16. http://drzewiecki-design.net

17. https://en.wikipedia.org/wiki/Airport

18. https://en.wikipedia.org/wiki/Scenery_generator

19. https://en.wikipedia.org/wiki/Weather

20. http://www.rexsimulations.com/weatherarchitect.html

21. http://www.flight1.com/products.asp?product=utxusa

22. http://www.opussoftware.co.uk/opusfsi.htm

23. https://www.pilots.shop/cms/Ui/Pages/Products/MainPage.aspx?id=253b8b5c-0a91-49358d01-b3c70aee6034

24. http://www.rexsimulations.com/weatherarchitect.html

25. http://fsqc.eu/?gclid=CjwKCAjwqLblBRBYEiwAV3pCJuGAlR19KQnowC5uBzx3gvHzR D-QtQG6p0H-C4NvM7ouAd3tGKamVRoCO6kQAvD_BwE

26. https://www.flightsim.com/vbfs/content.php?3473-FSClouds-And-Textures-Pro-98-NowFreeware

\section{УДК 656.7.052:004.4}

\section{Мансырова Севиль А.}

Национальная Академия Авиации, Баку, Азербайджан

avia-mexanik@mail.ru

\section{Практическое описание основных компонентов виртуальных симуляторов полета}

В этой статье описываются основные компоненты виртуальных тренажеров, то, как из них строится полноценно функционирующий тренажер. Основная цель виртуального симулятора - помочь пилоту приобрести, испытать и поддерживать навыки управления самолетом без какого-либо риска для имущества или жизни пассажиров и с гораздо меньшими затратами, чем обучение в воздухе.

Ключевые слова: виртуальный симулятор полета, 3D-очки, виртуальная кабина, набор программ, виртуальная реальность (VR), динамика полета, подготовка пилотов.

\section{UOT 656.7.052:004.4}

\section{Mansirova Sevil $\partial$.}

Milli Aviasiya Akademiyası, Bak1, Azərbaycan

avia-mexanik@mail.ru

\section{Virtual uçuş simulyatorlarının əsas komponentlərinin praktik təsviri}

$\mathrm{Bu}$ məqalədə virtual trenajorların əsas komponentləri və onların vasitəsi ilə tam funksional trenajorun yaradılmasından təsvir edilir. Virtual simulyatorun əsas məqsədi hər hansı mülki və həyati riski olmadan havada keçirilən təlimlərə nisbətən daha az məsrəflərlə pilota təyyarəni idarəetmə vərdişlərini aşılamaqdır.

Açar sözlor: Virtual uçuş simulyatoru, 3D gözlük, virtual kokpit, bir sıra proqramlar, virtual reallıq (VR), uçuş dinamikası, pilotların təlimi. 